\title{
DIARIO DE VIAJES
}

Leonora Esquivel*

\section{Salto al vacío}

Estaba ahí sentada en esa especie de iglú soterrado, aguardando la escena en la que tener los ojos cerrados o abiertos diera lo mismo.

Entonces sucedió, respiré profundo y me relajé. Poco después el crepitar de las rocas bañadas por el agua olorosa anunciaba el golpe de calor.

Como una mano que te cubre el rostro impidiendo la expansión de los pulmones, el vapor hirviente anunció el inicio del viaje.

En cuestión de segundos mi cuerpo era una montaña surcada por la que corrían veredas de gotas, comenzaba a salir aquello que no necesitaba y cualquier movimiento era cada vez más difícil de ejecutar.

Una semilla que cayó en la tierra, que eligió depositarse en un lugar preciso en un momento exacto. ¿Se darían las condiciones para su germinación? ¿Por qué tememos tanto a la muerte si al final es un salto a lo desconocido como lo es el nacimiento? No sabíamos qué nos esperaría y al final aquí estamos. Podría ser que el más allá fuera otra de esas decisiones inconscientes que tomó nuestra alma en un momento de silencio.

* Nació en la Ciudad de México en 1973. Es licenciada en filosofía por la UNAM y se doctoró en la Universidad Autónoma de Barcelona con una tesis sobre ética ambiental. Es cofundadora de AnimaNaturalis Internacional, organización hispanoamericana para los derechos de los animales. En 2013, ganó el Premio a la Sustentabilidad, categoría Mejor Activista. También es conferencista, conductora de televisión, psicoterapeuta corporal y coach ejecutiva. 
El tambor semejaba el latido de un corazón, víscera que marca el ritmo de nuestro ánimo: cambiante pero constante. Es curioso que hoy nos hastiemos pronto de todo, cuando durante nueve meses lo único que hicimos fue escuchar ese sonido y todo parecía estar en orden.

El aire era denso pero aromatizado por las hierbas que flotaban en el agua que daba de beber a las piedras. En mi espalda podía sentir las raíces que me rascaban como lo hacían mi abuela, mi madre, mi tía, en un gesto amoroso. Me volví el sedimento que sería nuevamente, cuando esta ilusión llegara a su fin y comenzara otra —o ninguna más.

En estas condiciones la mente no podía ir tan rápido como suele hacerlo, con su galopar incesante y desbordado, que nos damos a la tarea de domar, no siempre con éxito. Ese corcel se había detenido y las sensaciones lo inundaban todo haciendo necesaria una rendición total: permanecer como un árbol que existe sin juzgar.

Al final todo pasa, la incomodidad y su contrario, la carcajada y el drama, es cuestión de tiempo, de tener la suficiente paciencia para enfrentar la existencia y fluir en ella. No es tarea fácil, pero la confianza no radica en lo que sabemos, sino en el ímpetu con el que damos el salto hacia lo desconocido.

Lo hicimos antes, la vez primera, podemos hacerlo nuevamente, una y otra vez, sin miedo, con el corazón como guía y los ojos bien puestos 134 en la elección.

El espacio comenzó a tornarse pequeño, ese vientre no era suficiente para mi danza. Había que determinarse a salir — o a entrar- es todo tan relativo cuando se trata de tiempo y espacio...

Y ¿qué pasaría cuando ese otro sitio también me pareciera reducido? ¿Habría otro más amplio capaz de albergarme?

Tal vez eso sea la conciencia: un calzador que expande mi ser a tal punto que mi cuerpo más que un medio se vive como un obstáculo...

Y entonces lo abandonamos, como quien deja una flor a la vera de un camino, continuando sin ese lastre que en el mundo nos da tanto porque lo que buscamos ya no se encuentra con los ojos y lo único que puede contenernos es el gran abrazo del universo henchido. 


\section{Tengo los ojos llenos}

\section{A los animales que somos}

Cuando el polvo verde tocó mi lengua la sensación fue de asco, una especie de plasta amarga cubrió mis encías y fue necesario hacer un buche de agua para deglutirla. Miré el reloj y eran las 20:30. Solo había que esperar...

Entre miedo y expectativa transcurrió una hora hasta que de pronto una risa espontánea me invadió y comencé a mover los brazos como si rascara la tierra. En realidad estaba galopando pues era un caballo marrón. Sentí mi pelo a manera de crin cubrir mi rostro y mis cascos galopaban sobre un paraje. Era libre y veloz. Entonces recordé que lo primero que llamó mi atención al iniciar la caminata en las montañas fue descubrir un caballo en medio de un camino estrecho, como si lo estuviera custodiando. Yo era ese caballo.

De pronto vi frente a mis ojos cerrados un lobo y sentí en mi boca como crecían unos colmillos. "No quiero ser un animal que coma animales", me dije, pero dejé de resistirme y por un momento fui un lobo en la nieve. Solitario y con ojos amarillos, abría el hocico de vez en cuando para mostrar su dentadura.

Entonces el paisaje cambió y vi un mar fosforescente lleno de lucecitas de colores que supongo eran peces, pero yo no nadaba con ellos pues era un coral que se movía al vaivén de la marea. El agua pasaba a través de mí y mi estructura un poco rígida pero a la vez flexible me ayudaba a fluir en ese océano de luces.

Volví a la tierra y la sentí temblar a mi paso: era un bisonte. Mi cabeza estaba muy cerca del suelo y no tenía frío, era lento pero muy potente. Mientras andaba, todo retumbaba pero era sereno y su andar pausado me daba una sensación de seguridad, de estar bien plantada.

Sentí que algo colgaba de mi cara y fui un elefante de piel rugosa. La trompa se movía de un lado a otro descubriendo el entorno y podía oler el suelo, la tierra. Tuve miedo de que llegara un cazador y decidí disipar ese pensamiento. En esta ocasión el maltrato animal no se haría presente, a pesar de que al fondo sonaba una fiesta de pueblo donde se llevaba a cabo un jaripeo que estrujó mi corazón humano. 
Sentí pequeñas patas recorrer el suelo y fui un ciempiés. Era ágil y sus patas se movían rápidamente. Ser un artrópodo no es cosa menor, a pesar de su tamaño. Además el mundo cambia según tu perspectiva así que mi entorno no era el de un Homo sapiens, sino hierba y rocas, nada más. No existía ni el horizonte ni el cielo, solo lo inmediato, el aquí.

Luego creí ser una abeja, pero algo me tornó más humilde y fui mosca. No sentía realmente que volara, sino que revoloteaba en torno a algo o a alguien. Pasé rápidamente por esa forma y me pregunté por qué no había sido un ave todavía. Y de pronto me convertí en un cóndor que sobrevolaba la cordillera andina. Pude sentir cómo pasaba por estrechas cañadas y planeaba inclinándome de un lado hacia el otro, hasta desplazarme casi paralela a los muros de las montañas.

De golpe caí al suelo y me quedé inmóvil y pesada: era una roca. Era grato no moverse y saber que siempre estarás ahí si algo externo no te mueve. No tenía que elegir hacia dónde ir, era inútil, sólo tenía que permanecer así, quieta.

¿Por qué solo animales majestuosos?, pensé. Y fui una vaca que rumiaba su pasto. Con mis grandes ojos tiernos vi la hierba que comía y traté de no pensar en mi destino. Mis animales no morirían en manos humanas, no había nada que temer.

Entonces llegó una de las formas más disfrutables: el árbol. Sentí la fuerza de mi tronco bien enraizado en el suelo y cómo mis raíces llegaban muy profundo. Mis ramas se agitaban con el viento y escuchaba el aire cruzar entre mis hojas como un silbido de paz. Era una araucaria, árbol del sur de Chile, lugar al que quiero ir un día porque sé que ya estuve ahí.

Ser árbol fue lo que más me gustó, o mejor dicho con lo que me pude identificar más plenamente, y comprendí por qué sufro tanto cuando los derriban, porque una parte de mí es ellos y un árbol son todos, y cuando uno cae a todos nos duele y a los que no es porque no sienten, y no sienten porque tienen miedo, porque el miedo es un candado.

Decidí no tener miedo porque eso es lo que me dice la vejiga cuando me habla, me avisa que tengo miedo y cuando lo suelta ella me suelta, y soltamos lo que hay que soltar y seguimos.

El abuelo Don Julio nos guio hasta un pozo de agua de manantial donde en época de lluvia se forma una cascada y me ofreció un bautizo 
con un nombre náhuatl. Supongo puede ser un truco para el turista, pero me gustó que, sin conocerme, el que le fue dictado para mí fue Ce Calli que significa, "una casa, un hogar". Al principio esperaba algo más exótico como "princesa de la noche" o algo así, pero enseguida comprendí que los espíritus del lugar se referían a que yo soy una guardiana de este hogar, del planeta, de mi casa como templo para lo sagrado, y que mi búsqueda ha estado marcada por pertenecer, por hacer una madriguera, y que lo que hago con mis amigos y conmigo es brindar un espacio de hogar donde convivir y compartir. Yo soy mi casa, mi hogar.

En un momento del rito se dijeron unas frases de sabiduría lakota que me conmovieron hasta las lágrimas: "La tierra es mi cuerpo, el agua mi sangre, el aire mi aliento y el fuego mi espíritu. Nunca me iré de aquí, porque cuando muera seré nube, seré montaña, porque este es mi hogar y aquí pertenezco".

Entonces miré al cielo y lo vi a través de las ramas de un árbol de un verde deslumbrante, y supe que este es mi hogar, que no soy de otro lugar, que aquí es donde está lo que más quiero, lo que más me gusta, lo que defiendo y protejo porque es mío y soy yo.

El primer sentido que se me agudizó fue el oído y lo noté cuando los lametones de una perra se oían con eco, mucho más claras, y el crujir de las hojas secas bajo mis pies estaba intensificado. Cayó una rama frente a mí y su sonido fue más nítido. Esa sensación no duró mucho.

Cuando me recosté en la ladera de una montaña pude descansar sintiendo que la tierra me sostiene, que puedo confiar y entregarme a la vida, rendirme. Esa sensación de que ella va a estar ahí siempre, pase lo que pase, mueran los animales que mueran, caigan los árboles que caigan... Mi tarea es rendirme ante lo que es.

En la noche, cuando fui sola al baño, me encontré con una planta parecida a la cuna de Moisés y sentí su palpitar. Era una planta vanidosa pues me llamó para que la viera y parecía que se puso más grande y más hermosa cuando mis ojos se posaron en ella. Nada bello debería pasar desapercibido ante nuestros ojos. La belleza y el amor están ahí gritando para ser sentidos, pero nos da miedo, somos incapaces.

Puedo agradecer tener esa capacidad. Tal vez no supe hacerme millonaria trabajando, ni patino como estrella olímpica, ni pongo la 
frente en las rodillas, y las líneas de expresión se marcan bajo mis ojos, pero puedo hacer eso que muchos no pueden, que menos ven que puedo hacer. Sin embargo, están cerca de mí y quizá es porque esa belleza que capto la transmito de una u otra forma y es como si con gotero ellos pudieran estar cerca de lo hermoso, de lo puro, de lo genuino y yo, como todos, soy solo un vehículo.

Cuando abracé el árbol le pedí perdón por lo que mi especie les hace en nombre del progreso, y al abrir los ojos y ver un detalle de su tronco, fui levantando la vista poco a poco y mi mirada llegó hasta su copa. Pude captar que la vida es justo esa colección de pequeños momentos, breves presentes y que, si vivimos conscientemente cada uno de ellos, llegará un punto en que estaremos en la cima y habremos llegado a donde teníamos que llegar. De corteza en corteza se hace un tronco, de tronco en tronco crece un árbol y de árbol en árbol se hace un bosque, una selva.

Si en realidad todos somos uno y en el corazón no estamos separados, soy un ciempiés, un cóndor, un lobo, un bisonte, un elefante, una vaca, una piedra, un caballo, un árbol y también soy quien los cuida y quien los daña, quien los ve y los ignora, porque al final mi hogar es solo este instante en el que estoy conmigo y yo soy toda la belleza y todo el dolor que he visto y sentido. El afuera y los demás son únicamente pretextos, mensajeros para que yo sea todo lo que soy, todo lo que hay y habrá por siempre, porque no hay tiempo cuando eres alma.

Y esta alma que aprende y disfruta su camino es todas, así que al final nada es tan importante, ni tan grave; se trata solo de elegir dónde poner la energía y de qué llenar los ojos.

Los míos, como al verlos en un espejo esa noche, están llenos y todavía les cabe más

siempre porque ver con los ojos y con el alma es el don que tengo y tenemos

TODOS

UNO 